ORIGINAL ARTICLE

\title{
Knee disorders in the general population and their relation to occupation
}

\author{
P Baker, I Reading, C Cooper, D Coggon
}

Occup Environ Med 2003;60:794-797 See end of article for
authors' affiliations

Correspondence to: Professor C Cooper, Professor of

Rheumatology, MRC Environmental Epidemiology Unit, Southampton General Hospital, Southampton SOl6 6 YD, UK:

cc@mrc.soton.ac.uk

Accepted

12 September 2002

\begin{abstract}
Background: Hospital based studies of occupational risk factors for knee disorders are complicated by the possibility of selective referral to hospital of people whose work is made difficult by their symptoms.

Aims: To explore the extent of such bias and to assess the association of meniscal injury with occupational activities.

Methods: A questionnaire was mailed to a community sample of 2806 men aged 20-59 years in southern England. This asked about lifetime occupational and sporting activities, and any history of knee symptoms lasting 24 hours or longer. Rates of hospital referral were compared in symptomatic men according to their occupational activities. In a nested case-control investigation, the occupational activities of 67 men who reported meniscectomy were compared with those of 335 controls.

Results: Among 1404 men who responded to the questionnaire, the lifetime prevalence of knee symptoms was $54 \%$, and in $70 \%$ of cases the symptoms had started suddenly, usually while playing sport. Symptomatic men whose work entailed kneeling or squatting were more likely to be referred to an orthopaedic surgeon than the average ( $28 \%$ and $31 \%$ versus $24 \%)$, especially if they experienced locking of the knee $(69 \%$ and $73 \%$ versus $43 \%)$. In the nested case-control study, meniscectomy was associated with playing soccer and work that involved regular kneeling or squatting.

Conclusions: Results suggest that hospital referral for knee symptoms is influenced to some extent by patients' occupational activities. Playing soccer is confirmed as a strong risk factor for knee cartilage injury.
\end{abstract}

$P$ ain in the knee can arise from various disorders including inflammatory and degenerative arthritis, bursitis, and injury to cartilage, ligaments, or other structures in and around the joint. Elsewhere, we have reported a prospective case-control study of hospital treated meniscal injury that indicated associations with prolonged kneeling or squatting at work, and with several other occupational activities. ${ }^{1}$ Interpretation of such studies is complicated, however, by the possibility that people who are handicapped occupationally by knee symptoms may be more likely to seek and obtain medical treatment. Thus, if meniscal injuries make kneeling and squatting difficult, patients whose work involves these activities might be differentially referred to hospital. As a consequence, risk estimates would be spuriously inflated.

To explore whether this is an important source of bias, and to examine further the association between meniscal injury and occupational activities, we carried out a postal survey of men of working age from the same community as was studied in our prospective case-control investigation.

\section{MATERIALS AND METHODS}

The study sample comprised a random one in six sample of men aged 20-59 years selected from the registration lists of eight general practices in southern Hampshire (in Britain almost everyone is registered with a general practitioner). The names of the men chosen were checked by their general practitioners to exclude any who should not be contacted, for example because of recent major illness. The remainder were sent a postal questionnaire, followed if necessary by a reminder after four weeks.

The questionnaire asked about lifetime occupational and sporting history and lifetime history of knee symptoms lasting 24 hours or longer. For each job that had been held for at least 12 months, we requested the age of starting and finishing and whether an average working day had involved any of 10 specified physical activities. Similarly, for each sport that had been played more than five times per year, we asked the ages at which the subject began and ended this level of participation. Subjects who reported knee symptoms were asked further about their duration, their impact on employment, and whether they had led to the use of various medical services. Where surgery had been carried out to the knee, we asked about the nature of the operation.

From the information obtained, we calculated the prevalence of knee symptoms and associated disability, and assessed the use of medical services according to the types of occupation that subjects had held at the birthday preceding the onset of their symptoms and their sporting activities at that time.

In addition, the association of knee cartilage injury with sporting and occupational activities was examined in a nested case-control study. For each man who reported undergoing meniscectomy we randomly selected five controls, matched to within one year of age, from the pool of subjects who had not undergone the operation. From their occupational and sporting histories we then identified activities to which the cases were exposed at the birthday preceding the onset of their symptoms. We also classified them according to whether they worked in any of a predefined list of occupations (coded according to the Office of Population Censuses and Surveys 1991 classification scheme $^{2}$ ) in which prolonged kneeling and squatting was likely to occur. This was the same set of occupations as had been found commonly to involve these activities in the prospective case-control study of hospital treated knee cartilage injury that was carried out in parallel with the current investigation. ${ }^{1}$ The occupational and sporting activities of controls were ascertained for the same birthday as their matched case. Associations between meniscal injury 
Main messages

- The lifetime prevalence of knee symptoms among men aged $20-59$ years is high (54\%).

- Seventy per cent of cases have sudden onset of symptoms.

- Meniscectomy is an important consequence of these symptoms.

- Meniscectomy is associated with playing soccer and work that involves regular kneeling or squatting.

- Hospital referral for knee symptoms is influenced to some extent by patients' occupational activities.

and occupational and sporting activities were assessed by conditional logistic regression, and summarised by odds ratios (OR) with $95 \%$ confidence intervals (CI).

\section{RESULTS}

A total of 2806 men were selected from the general practice lists, but on the advice of their general practitioners, 72 were excluded from the mailing. Of the 2734 questionnaires sent, 237 were returned because the subject had moved without giving a forwarding address, 1093 were not answered for other reasons, and 1404 (50\% of the original sample) were satisfactorily completed. The ages of the responders at the time of answering the questionnaire ranged from 20 to 60 years with a mean of 41.6 and median of 42.5 years.

Among the responders, 762 (54\%) reported one or more knee symptoms at some time in their life, including 454 $(32 \%)$ with symptoms in the past year and 264 (19\%) with symptoms in the past month. The lifetime prevalence in the 509 men who only responded after a reminder (53\%) was little different from that in those who replied to the first mailing (55\%).

Table 1 shows the frequency with which individual symptoms were reported. Pain and stiffness were the most common symptoms, while locking occurred least often. The prevalence of symptoms, even over a lifetime, varied little with age. Of the 762 men who had suffered from knee symptoms, $531(70 \%)$ indicated that these had started suddenly, usually while they were participating in soccer (108), running (32), rugby (32), or some other sport (71). In addition, 118 reported sudden onset while they were at work. Eighty six men $(6 \%)$ had at some time had to modify their work in response to knee problems, most often because of difficulty with climbing, lifting, or kneeling. Knee disorders had caused 202 men (14\%) to miss time from work (median days lost over working life $=14)$, and $20(1 \%)$ to leave a job.

Many of those who answered the questionnaire had sought medical treatment for knee symptoms. Thus, 438 (31\%) had consulted a general practitioner, $222(16 \%)$ had attended a hospital clinic, 182 (13\%) had seen an orthopaedic surgeon, and $119(8 \%)$ had undergone knee surgery. These included 67 men $(4.8 \%)$ treated by meniscectomy. Among the latter, locking was a notably more common symptom than in men whose knee symptoms had not led to meniscectomy (lifetime prevalence $42 \%$ versus $14 \%$ ).

Table 2 gives the frequency of medical consultation for knee symptoms according to whether men were exposed to specified occupational activities in the job that they held at the birthday before their symptoms started. The proportion of symptomatic men who consulted a general practitioner showed little variation in relation to occupational activities, but those whose jobs involved kneeling or squatting were somewhat more likely to be referred to an orthopaedic
Policy implications

- Knee pain is a common occupational symptom.

- Work involving regular kneeling or squatting is associated with an increased risk of knee pain and meniscectomy.

- Preventive measures against this outcome are urgently required.

Table 1 Lifetime and recent prevalence of knee symptoms in 1404 responders

\begin{tabular}{llll}
\hline \multirow{4}{*}{ Symptom } & \multicolumn{3}{l}{ Prevalence $(\%)$} \\
\cline { 2 - 4 } & Lifetime & Past year & Past month \\
\hline Pain & 45 & 28 & 17 \\
Stiffness & 37 & 24 & 14 \\
Swelling & 27 & 15 & 10 \\
Giving way & 20 & 14 & 9 \\
Grating & 17 & 12 & 8 \\
Locking & 9 & 5 & 3 \\
Any symptom & 54 & 32 & 19 \\
\hline
\end{tabular}

surgeon ( $28 \%$ and $31 \%$ respectively) than the overall average $(24 \%)$. In men with locking of the knee this differential was more marked $(69 \%$ and $73 \%$ versus $43 \%$ overall), and referral to an orthopaedic surgeon was also more common in those who played soccer $(62 \%)$ and rugby $(55 \%)$.

The nested case-control study compared the 67 men who had undergone meniscectomy with 335 controls. The ages at which the cases' symptoms had begun ranged from 8 to 44 years with a median of 22 years. Table 3 shows the relation of meniscal injury to sporting activities. A strong association was found with participation in soccer (OR 6.9, 95\% CI 3.5 to 13.3 ), and risk was also significantly increased in rugby players (OR $3.4,95 \%$ CI 1.5 to 7.8 ).

Table 4 summarises the association of meniscal injury with occupational activities after adjustment for participation in sports. Increased risks were found with prolonged kneeling (OR 2.5, 95\% CI 1.3 to 4.8 ) and squatting (OR 2.5, 95\% CI 1.2 to 4.9 ) at work, frequent climbing of stairs (OR 2.0, 95\% CI 1.0 to 4.1 ), and with work in jobs that had been classed as likely to entail kneeling or squatting (OR 2.3, 95\% CI 1.1 to 4.8). We looked to see whether risks were particularly high in men who played soccer as well as being exposed to kneeling or squatting at work, but there was no evidence of an interaction of this type.

\section{DISCUSSION}

This survey indicates a high prevalence of knee symptoms among men of working age. It supports the findings of our prospective case-control study that surgically treated meniscal injury is associated with sporting activities (especially soccer and rugby) and with occupational kneeling and squatting. ${ }^{1}$ However, it suggests that part of the risk associated with occupational kneeling and squatting results from differential referral to hospital of cases whose work involves these activities.

The response to the questionnaire (50\%) was lower than is normally obtained in surveys of women and older men, and there may have been a tendency for subjects with a history of knee problems to respond more readily than those without. However, even when this is taken into account, the 
Table 2 Frequency of medical consultation for knee symptoms according to occupational activities in the job held at the birthday before symptoms began

\begin{tabular}{|c|c|c|c|c|c|c|}
\hline \multirow[b]{2}{*}{ Occupational activity (in an average working day) } & \multicolumn{3}{|c|}{ Men with any knee symptom } & \multicolumn{3}{|c|}{ Men with locking } \\
\hline & $\begin{array}{l}\text { No. of men } \\
\text { exposed to } \\
\text { activity }\end{array}$ & $\begin{array}{l}\% \text { consulted } \\
\text { general } \\
\text { practitioner }\end{array}$ & $\begin{array}{l}\% \text { consulted } \\
\text { orthopaedic } \\
\text { surgeon }\end{array}$ & $\begin{array}{l}\text { No. of men } \\
\text { exposed to } \\
\text { activity }\end{array}$ & $\begin{array}{l}\% \text { consulted } \\
\text { general } \\
\text { practitioner }\end{array}$ & $\begin{array}{l}\% \text { consulted } \\
\text { orthopaedic } \\
\text { surgeon }\end{array}$ \\
\hline Sitting for $>2$ hours in total & 316 & 53 & 22 & 44 & 61 & 34 \\
\hline Standing or walking for $>2$ hours in total & 461 & 56 & 25 & 71 & 73 & 54 \\
\hline Kneeling for $>1$ hour in total & 159 & 57 & 28 & 29 & 79 & 69 \\
\hline Squatting for $>1$ hour in total & 147 & 58 & 31 & 30 & 80 & 73 \\
\hline Getting up from kneeling or squatting $>30$ times & 210 & 54 & 28 & 36 & 75 & 64 \\
\hline Driving for $>4$ hours in total & 113 & 56 & 25 & 22 & 55 & 41 \\
\hline Walking for $>2$ miles in total & 266 & 56 & 27 & 43 & 72 & 60 \\
\hline Climbing $>30$ flights of stairs & 152 & 58 & 28 & 17 & 88 & 59 \\
\hline Lifting or moving weights of $10+\mathrm{kg}$ by hand & 318 & 56 & 25 & 49 & 71 & 57 \\
\hline Liffing or moving weights of $25+\mathrm{kg}$ by hand & 241 & 54 & 26 & 37 & 68 & 54 \\
\hline All men & 762 & 57 & 24 & 127 & 72 & 43 \\
\hline
\end{tabular}

Table 3 Associations of meniscal injury with participation in sports

\begin{tabular}{llll}
\hline Sport & $\begin{array}{l}\text { No. of } \\
\text { cases } \\
\text { exposed }\end{array}$ & $\begin{array}{l}\text { No. of controls } \\
\text { exposed }\end{array}$ & OR (95\% CI) \\
\hline Soccer & 36 & 62 & $6.9(3.5$ to 13.3) \\
Rugby & 11 & 20 & $3.4(1.5$ to 7.8$)$ \\
Running & 6 & 22 & $1.4(0.5$ to 3.7$)$ \\
Swimming & 14 & 47 & $1.6(0.8$ to 3.0$)$ \\
Other & 38 & 132 & $2.1(1.2$ to 3.6$)$ \\
\hline
\end{tabular}

Each sport was examined in a separate regression model. Subjects were classified as exposed to a sport if they engaged in it at least five times per year at the age when they or their matched case first developed knee symptoms. For further details see text.

prevalence of reported symptoms and disability was remarkably high. Thus, $14 \%$ of the men who answered the questionnaire had at some time been absent from work because of a knee problem, and $8 \%$ had undergone knee surgery. These data are comparable with other population based estimates. ${ }^{3}{ }^{4}$ The major impact of knee disorders on capacity to work and demand for health services emphasises the need for effective preventive strategies.

The nested case-control analysis of meniscal injuries complements our prospective case-control study of surgically treated knee cartilage disorders in the same community. ${ }^{1}$ It is weaker than the other study in so far as information about previous meniscectomy depended on subjects' recall, and fewer cases were available for study. On the other hand, differential recruitment to the study of cases from manual occupations or controls from non-manual jobs was less likely.

Because of the possibility of recall bias, we did not ask subjects directly about the work that they were doing when their symptoms began, and this meant that exposure to activities had to be inferred from those reported in the job held at the birthday preceding the onset of symptoms. A few subjects may have changed their job between their birthday and developing their knee disorder, but any resultant misclassification of exposure is likely to have biased risk estimates towards the null rather than cause spurious associations.

Even with the method of data collection adopted, it is still possible that cases recalled exposures to occupational activities more completely than controls, perhaps because their knee disorder made certain tasks difficult or impossible. Importantly, however, an association was found not only with reported kneeling and squatting, but also with work in jobs in which these activities are common. Biased recall of job title seems much less likely.

The increased risk of meniscal injury with participation in soccer and rugby was similar to that in our prospective casecontrol study. ${ }^{1}$ It appears to result from episodes of acute trauma while engaged in these sports, and in that study we found no evidence that soccer players are at increased risk of meniscal injuries other than when they are playing. Risk estimates may have been exaggerated by differential referral of sportsmen to orthopaedic surgeons, but bias of this sort is unlikely to account for more than a small part of the observed association with soccer.

Table 4 Associations of meniscal injury with occupational activities

\begin{tabular}{llll}
\hline Occupational activity (in an average working day) & $\begin{array}{l}\text { No. of cases } \\
\text { exposed }\end{array}$ & $\begin{array}{l}\text { No. of controls } \\
\text { exposed }\end{array}$ & OR (95\% CI) \\
\hline Sitting for $>2$ hours in total & 26 & 150 & $0.8(0.4$ to 1.6) \\
Standing or walking for $>2$ hours in total & 43 & 184 & $1.5(0.8$ to 3.1$)$ \\
Kneeling for $>1$ hour in total & 23 & 56 & $2.5(1.3$ to 4.8$)$ \\
Squatting for $>1$ hour in total & 20 & 47 & $2.5(1.2$ to 4.9$)$ \\
Getting up from kneeling or squatting $>30$ times & 23 & 76 & $1.9(1.0$ to 3.8$)$ \\
Driving for $>4$ hours in total & 8 & 40 & $0.9(0.4$ to 2.1) \\
Walking for $>2$ miles in total & 25 & 102 & $1.1(0.6$ to 2.2$)$ \\
Climbing $>30$ flights of stairs & 18 & 59 & $2.0(1.0$ to 4.1$)$ \\
Lifting or moving weights of 10+ kg by hand & 31 & 120 & $1.7(0.9$ to 3.1$)$ \\
Lifting or moving weights of $25+\mathrm{kg}$ by hand & 20 & 86 & $1.3(0.7$ to 2.5$)$ \\
Work in an occupation likely to involve kneeling or squatting & 17 & 61 & $2.3(1.1$ to 4.8) \\
\hline
\end{tabular}

*For definition see text.

Each occupational activity was analysed in a separate regression model with adjustment for participation in sport (soccer, other, none). Subjects were classified as exposed to an activity if they reported it at the birthday preceding the onset of their symptoms or those of their matched case. 
The association of meniscal injury with occupational kneeling and squatting was present after adjustment for possible confounding effects of sporting activity, and again is consistent with the findings of our prospective case-control study as well as other investigations. ${ }^{5-8}$ However, the data summarised in table 2 suggest that men with knee symptoms, and particularly those with locking, which was the complaint most specifically related to meniscal injury, are more likely to be referred to an orthopaedic surgeon if their work involves kneeling and squatting. The effect of such differential referral would be to inflate risk estimates.

In a retrospective study of this type it is impossible to determine which and how many subjects with meniscal injuries never reach an orthopaedic surgeon, and therefore go undiagnosed. Thus, the extent of any bias from differential referral cannot be estimated with confidence. However, it would have to be substantial to explain completely the associations with meniscectomy that we have observed.

This survey provides further support for efforts to reduce prolonged kneeling and squatting in the workplace where it is practical. Whether the risks associated with these activities are sufficient to justify the classification of meniscal injury as an occupational disease for social security purposes is not yet clear. To answer this question it may be necessary to carry out a prospective cohort study with systematic investigation of knee disorders as they occur.

\section{ACKNOWLEDGEMENTS}

Paul Baker was supported by an Esso Fellowship awarded through the Royal College of Physicians Faculty of Occupational Medicine. Isabel Reading was supported by the Colt Foundation. We are grateful to the general practitioners who allowed us to approach their patients.

\section{Authors' affiliations}

P Baker, I Reading, C Cooper, D Coggon, MRC Environmental Epidemiology Unit, University of Southampton, Southampton General Hospital, Southampton, UK

\section{REFERENCES}

1 Baker P, Coggon D, Reading I, et al. Sports injury, occupational physical activity, joint laxity and meniscal damage. J Rheumatol 2002;29:557-63.

2 Office of Population Censuses and Surveys. Standard occupational classification. London: HMSO, 1991.

3 Badley EM, Tennant A. The changing profile of joint troubles with age: findings from a postal survey of the population. Ann Rheum Dis 1992:51:366-71.

4 Dieppe P, Basler HD, Chard J, et al. Knee replacement surgery for osteoarthritis: effectiveness and practice variations, indications and possible determinants of utilisation. Rheumatology 1999;38:73-83.

5 Sharrard WJW, Liddell FDK. Injuries to the semilunar cartilages of the knee in miners. Br J Ind Med 1962;19:195-202.

6 Greinemann H. Argumente gegen die Anerkennung von Kniegelenkarthrosen nach Berufsbelastung als Berufskrankheit. Unfallchirurg 1988;91:374-80

7 Kivimaki J, Riihimaki H, Hanninan K. Knee disorders in carpet and floor layers and painters. Scand J Work Environ Health 1992;18:310-16.

8 Jensen L, Eenberg W. Occupation as a risk factor for knee disorders. Scand J Work Environ Health 1996;22:165-75.

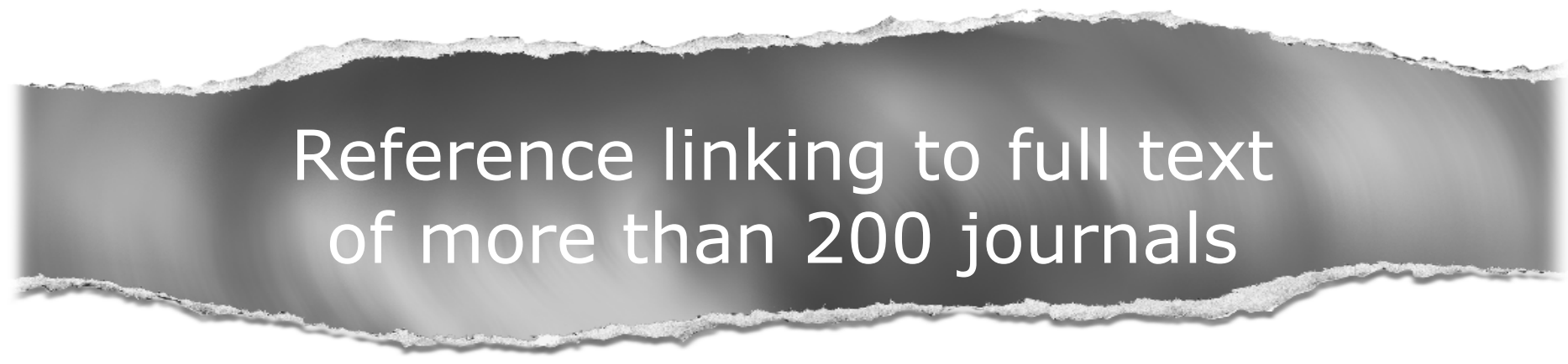

\section{Toll free links}

You can access the FULL TEXT of articles cited in Occupational and Environmental Medicine online if the citation is to one of the more than 200 journals hosted by HighWire (http://highwire.stanford.edu) without a subscription to that journal. There are also direct links from references to the Medline abstract for other titles.

www.occenvmed.com 